\title{
Complexidade e experiências formativas
}

\section{Roque Strieder* \\ Clenio Lago**}

Paulino Eidt ${ }^{* * * * *}$

\begin{abstract}
Resumo
A contemporaneidade se caracteriza pela instabilidade e pela diversidade, colocando em questão certezas e verdades propostas na modernidade. Reconhecemos que a realidade das coisas e dos fenômenos se efetiva como um tecido de acontecimentos, ações, interações, retroações e acasos. Essa diferente moldura alarga a necessidade de revisão dos alicerces epistemológicos que sustentam as práticas educacionais e lhes dão sentido. O pensamento complexo é uma opção alternativa por atuar como contraponto à ciência clássica e sua lógica reducionista e de compartimentalização dos conhecimentos, bem como por responder aos desafios epistemológicos e educacionais contemporâneos. Ele visa associar diversas áreas e formas de conhecimento, sem, no entanto, fundi-las, distinguindo sem separar as diversas disciplinas e instâncias das realidades. $\mathrm{O}$ estudo, baseado em referenciais teóricos, evidencia a relevância das abordagens complexas como suporte de experiências formativas porque também capazes de produzir complexidades nas reflexões sobre problemáticas educacionais. Concluímos que as possibilidades formativas a partir da complexidade potencializam a ressignificação da concepção de ser humano e a compreensão de sua singularidade na interdependência; o entendimento de que ações pedagógicas e educativas são uma constante interrogação sobre as possibilidades de conhecer o conhecimento e de ressignificar o aprender, para muito além de conhecer suas funções e finalidades utilitaristas; e, como possibilidade formativa, nos coloca na trilha da responsabilidade, não como algo eventual, mas presente e indicativa da liberdade para escolher ficar ou ir além.
\end{abstract}

Palavras-chave: Educação. Complexidade. Experiências formativas.

\footnotetext{
* Doutor em Educação pela Universidade Metodista de Piracicaba (UNIMEP/SP). Professor do Programa de Mestrado em Educação da Universidade do Oeste de Santa Catarina (UNOESC).

** Doutor em Educação pela Pontifícia Universidade Católica Rio Grande do Sul (PUC/RS). Atua junto ao Programa de Mestrado em Educação da Universidade do Oeste de Santa Catarina (UNOESC).

${ }^{* * *}$ Doutor em Ciências Sociais pela PUC/SP. Atua junto ao Programa de Mestrado em Educação da Unoesc.
} 
http://dx.doi.org/10.5007/2175-795X.2016v34n2p338 


\section{Considerações iniciais}

Vamos considerar, como ponto de partida, que toda e qualquer atividade escolar e educacional tenha como compromisso e seja corresponsável pela e com a construção de conhecimentos, para muito além do enfoque, prioritário na atualidade, sobre habilidades e competências. Referimo-nos aos conhecimentos que contemplam em seu potencial o desenvolvimento humano, de não somente conhecer realidades, mas de compreendê-las.

Trata-se de um desafio da educação escolar para com uma aprendizagem que possibilite aos seres humanos - estudantes - a compreensão da dinâmica implicada nos processos de construção dos conhecimentos, bem como para com a condição humana.

A lógica da tradição escolar moderna, seguindo os ditames de uma concepção de ciência fragmentária e simplificadora, priorizou visões mutiladas (MORIN, 2002), reducionistas e descontextualizadas, simplificando realidades, simplificando fenômenos naturais, fenômenos sociais, ambientais e políticos, e a própria condição existencial do ser humano. Essa lógica fragmentária também conduziu os seres humanos a desenvolverem ações mutiladoras, mecanicistas e instrumentalizadas. Com um caminhar à semelhança da ciência moderna e suas bases fragmentárias, a cultura escolar segue supervalorizando a técnica e um fazer pedagógico e educativo vinculado à especialidade, fidelizada ao slogan do quanto mais específico for um conhecimento, maior seu grau de utilidade e pertinência.

Amparada no paradigma da racionalidade instrumental, a cultura escolar, focada em programas unidirecionais de desenvolvimento tecnocientífico, em estreita associação com uma ciência simplificadora e fragmentadora, persiste contribuindo para a construção de ideários formativos e sociais que desconsideram a complexidade das realidades, a complexidade dos contextos sociais, da ética e da política, bem como da condição humana.

Para Morin (2002), mais do que transmitir pacotes de informações, mais do que conhecer coisas e os conteúdos das realidades naturais e culturais, a educação escolar precisa oportunizar a aprendizagem sobre as várias formas de se relacionar com os conhecimentos e com as realidades, sejam elas naturais ou culturais. Pacotes de informações ou de conhecimentos prontos sustentam a concepção da existência da verdade incondicional sobre o contexto natural, bem como sobre o contexto cultural e humano. Ao fazê-lo, cria imaginários que negligenciam rigorosamente serem as realidades naturais e culturais frutos de processos vivenciados como experiências humanas.

Mais do que consolidar verdades absolutas, de base racionalista, sobre realidades também absolutas, cabe à educação escolar contribuir para o reconhecimento de que as realidades não têm consistência que 
lhes possa assegurar certezas e permanências conceituais. Para Wolfgang Welsch (2007, p. 251), filósofo alemão, as "estruturas da racionalidade são sempre associadas com práticas culturalmente compartilhadas e, inversamente, culturas podem ser concebidas como formas de racionalidade".

Diante do convite à "não rendição" ao uso funcional e tecnicista do conhecimento, que insiste em submeter o estudante a um programa de aprendizagem para "se dar bem na vida" e ser capaz de contribuir para o progresso econômico de sua comunidade, como repensar o conhecimento implicado nos processos da educação escolar? Quais são as possibilidades de transformar a educação escolar em um manancial de reflexões sobre os conhecimentos, tendo como base o paradigma da complexidade teorizado por Morin? Quais desafios, dentro desse contexto, colocam-se diante dos educadores, agora comprometidos com conhecimentos capazes de contribuir com a sua realização, bem como com a dos estudantes, enquanto seres humanos?

Essas são questões de investigação neste estudo e, ao mesmo tempo, indicadoras de sugestão sobre abordagens de conhecimentos no processo da educação escolar. Nossa sugestão é um convite para o reconhecimento da complexidade e das interdependências das realidades, sejam elas naturais e/ou oriundas das formas de organização humanas. Tem como referência os estudos de Edgar Morin e a ideia de como a emergência conceitual da complexidade pode implicar a revitalização dos sentidos da educação escolar para com a realização humana.

Importa compreender melhor os propósitos da ciência na modernidade, qual seja, de garantir, ao descrever a realidade a partir da experiência e da observação, via procedimentos racionais, a produção e a validade dos conhecimentos. Compreender as implicações, na educação escolar, do domínio de procedimentos empíricos e da aposta na objetividade, que firma a separação entre sujeito e objeto.

Compreender melhor como conhecimentos interdependentes, sobre realidades também interconectadas, são fragmentados em um arquipélago de disciplinas e, por isso mesmo, forçam a redução das atividades da educação escolar a meras sessões de transmissão de pacotes de saberes distintos, prontos e completos. E, ainda, entender como essa transmissão fragmentária se faz na forma de habilidades e competências técnicas capazes de potencializar o fazer profissional em detrimento de um desenvolvimento humano.

\section{Nas teias da complexidade}

O paradigma newtoniano/cartesiano contém princípios, como obscuros núcleos orientadores do discurso teórico (MORIN, 2001, p. 45) que constitui a modernidade. ${ }^{1}$ Princípios que têm como sustento operacional a lógica do cálculo, da simplificação fragmentária e da formalização. Morin (2001) coloca 
em questão esses princípios e propõe o combate à lógica simplificadora e reducionista do determinismo e da fragmentação da realidade, manifestamente presentes nesse paradigma hegemônico da ciência moderna. Também apresenta e reafirma a necessidade de superar as implicações resultantes do paradigma hegemônico da ciência moderna, como a dominação hierárquica, a sujeição e a servilidade cegas.

Para o autor, no princípio da separação é necessário analisar cada parte de um fenômeno em separado para melhor conhecê-lo. É esse princípio da disjunção que separou as áreas do conhecimento e conduziu-o para o âmbito da hiperespecialização.

Para Morin (2004, p. 13), "De fato a hiperespecialização impede tanto a percepção do global (que ela fragmenta em parcelas), bem como o essencial (que ela dilui)." A cultura da hiperespecialização, sem negligenciar as inúmeras contribuições em todos os âmbitos da vida humana, da produção e da tecnociência, resta insuficiente para compreensões mais alargadas das complexas tramas da dinâmica da vida, da dinâmica do entorno ambiental, da dinâmica da produção econômica e da dinâmica das inter-relações humanas. Para Japiassú (2006, p. 28-29), a fragmentação levou os saberes ao leito dos enfermos e deflagrou

A situação patológica em que se encontra nosso saber. A especialização sem limites culminou numa fragmentação crescente do horizonte epistemológico. Chegamos a um ponto em que o especialista se reduz ao indivíduo, que à custa de saber cada vez mais sobre cada vez menos, termina por saber tudo (ou quase tudo) sobre o nada, em reação ao generalista que sabe quase nada sobre tudo. [...] o desenvolvimento da especialização, com todos os seus inegáveis méritos, repartiu ao infinito o território do saber.

Na modernidade, o princípio da ordem, que induz, como consequência, à estabilidade e à objetividade, torna-se soberano como modelo e critério de explicação definitiva do real. Uma explicação que leva ao determinismo universal, o que significa a necessária exclusão da possibilidade do acaso, da incerteza e das emergências. Os princípios que reduzem e fragmentam são o cerne do paradigma da simplificação e são formulados com base em uma visão científica de natureza sólida, obedecendo ao princípio da estabilidade e da ordem.

As rupturas antropológicas e cosmológicas necessárias para a hegemonia do paradigma newtoniano/cartesiano resultaram em duas epistemologias básicas, que caracterizam a modernidade. São elas: o racionalismo (res cogitans) e o empirismo (res extensa). ${ }^{2} \mathrm{O}$ racionalismo, cuja predominância torna-se hegemônica a partir do século XVII, firma-se na convicção epistemológica que vê no pensamento racional a principal fonte para a construção do conhecimento humano. Essa predominância se estende até o século XIX, quando começa a dar lugar à epistemologia empirista. O 
empirismo sustenta-se no experimento como base e fonte única para a construção do conhecimento humano.

Racionalistas e empiristas apregoam serem eles as únicas fontes inquestionáveis de respostas capazes de solucionar os grandes problemas da humanidade, sejam eles de ordem econômica/produtiva, sejam de ordem social e/ou formativa humana. Seus adeptos estão convencidos de que essas bases estruturais, que garantem a construção de conhecimentos, são indubitáveis e o único conhecimento válido é aquele obtido dentro dessa sistemática.

Porém tanto o racionalismo quanto o empirismo, como fontes da verdade inquestionável, produzem visões "cada vez mais simplificadoras para as sociedades cada vez mais complexas. Produzem visões cada vez mais unidimensionais para sociedades mais multidimensionais", como escreve Morin (1986, p. 154). Na mesma linha, o pensamento Charles Snow (1995, p. 72) evidencia que "quando esses dois sentidos se desenvolvem separados, nenhuma sociedade é capaz de pensar com sabedoria".

A validação inquestionável do conhecimento produzido em forma de pacotes completos e prontos cria de forma densa, em termos de visão cosmológica e antropológica, a concepção de igualdade universal. Uma igualdade que evidencia o triunfo da razão como forma de organização da vida social coletiva, exigindo o desaparecimento das diferenças e da alteridade. O outro é reduzido a um igual a mim, a alguém feito à minha imagem e semelhança, o que o faz desaparecer como um em si mesmo. Esse individualismo universal é gerador de sentimentos que levam à invisibilidade das diferenças singulares. São sentimentos que resultam do exercício dos direitos e das liberdades individuais, que tendem a criar cegueiras generalizadas em grandes parcelas da população, com a disseminação de práticas discriminatórias.

A simplificação, a hiperespecialização, o individualismo e a excessiva compartimentalização do conhecimento não nos conduziram somente ao esplendor da civilização, mas também à barbárie, afirma Morin (1986). A geopolítica do caos se expressa na escravidão do ser humano moderno, na erosão da subjetividade e na extinção de espécies vegetais e animais. Rossi (2000, p. 130) sinaliza que "o que é moderno não coincide mais com o que é humano". E preconiza: "olhar para o futuro assemelha-se a uma viagem oceânica em frágeis caravelas".

Significa que a perspectiva convencional de separação desfigurou a racionalidade, colocando em questão o próprio paradigma moderno de conhecimento. A ciência precisa, proposta pela modernidade, com sua forma de pensar simplificadora e firmada na perspectiva de separações, é 
progressivamente considerada insuficiente e repleta de carências. Em vários âmbitos dos sentires e dos fazeres humanos, que intencionalmente reforçam a instrumentalização e os conhecimentos voltados para fins técnicos, se reconhecem limites e insuficiências. As ciências, sejam as naturais, as sociais ou as humanas, reconhecem que seu desenvolvimento ultrapassa a forma racional, linear e amparada em base unificada, pois o pensamento que simplifica também promove um conhecimento fragmentado, e este alimenta um pensamento simplificador.

Esse pensar simplificador, que embasa o paradigma cartesiano, não é suficiente para atender à complexa demanda globalizante das problemáticas políticas, sociais, ambientais e éticas da contemporaneidade, como enfatiza Lévy (1998, p. 61):

Os grandes problemas políticos do mundo contemporâneo referem-se ao desarmamento, aos equilíbrios ecológicos, às mutações da economia e do trabalho, ao desenvolvimento dos países do hemisfério sul, à educação, à miséria, à manutenção do laço social etc. Ninguém possui a solução simples e definitiva para resolvê-los. [...] Além disso, os problemas em questão estão todos, em maior ou menor medida, interconectados em um espaço mundializado. Enfim, sua resolução exige negociações entre atores muito numerosos, de porte, cultura e interesses a curto prazo heterogêneos. Praticamente nenhum sistema de governo contemporâneo foi concebido de modo a responder a tais exigências.

Fica evidenciado o reconhecimento de que, na atualidade, nos encontramos efetivamente cada vez mais confrontados com problemas abrangentes, complexos e resultantes de entrelaçamentos. E essa constatação faz Welsch (2007, p. 243) afirmar ser “importante abandonar o dogma da separação, terminar com o pensamento dissecante".

Assim, diante de problemáticas - todas com elevado grau de interdependência - que fazem e envolvem as sociedades amplas e complexas da atualidade, torna-se necessária uma nova forma de pensar que permita visões de conjunto, para então criar estratégias alternativas para realidades instáveis e flutuantes. Na reflexão de Prigogine (1996, p. 12), “A ciência clássica privilegiava a ordem, a estabilidade, ao passo que em todos os níveis de observação reconhecemos agora o papel primordial das flutuações e da instabilidade".

Ou seja, diante de realidades complexas toda e qualquer descrição e explicação analítica, com base em modelos simplificadores, que analisam cada parte sem descrever o todo e pretendem compreender o todo desconsiderando as partes, são insuficientes e passíveis de falhas. Desejar compreender o que é complexo, por natureza, requer um pensamento complexo.

Esse desejo de compreensão permitiu o surgimento de uma nova ciência, que não exclui o pensamento linear-cartesiano, mas reconhece que o isolamento que o acompanha não é suficiente para 
lidar com a complexidade, a diversidade e a imprevisibilidade do mundo. Nas palavras de Prigogine (1996, p. 11):

Ao longo das últimas décadas, nasceu uma nova ciência, a física dos processos de nãoequilíbrio. Esta ciência revelou conceitos novos, como a auto-organização e as estruturas dissipativas, que são hoje amplamente utilizados em áreas que vão da cosmologia até a ecologia e as Ciências Sociais, passando pela Química e pela Biologia.

Uma nova ciência cuja visão é capaz de compreender melhor o conjunto das contradições, das ambiguidades e das interdependências requer como referência a complexidade, e não a simplificação. Essa necessidade de desenvolvimento do pensamento complexo se justifica diante da também complexidade inerente aos fenômenos naturais e sociais, bem como da complexidade das organizações humanas. O próprio modo de conceber o desenvolvimento científico, incluindo as concepções de relatividade e de entropia, admite as irreversibilidades e as probabilidades como formas de entender o universo e as realidades em sua dinâmica evolutiva, algo impossível quando concebidas como estáticas e determinadas mecanicamente.

Como criador e artífice da concepção de complexidade, Morin a entende como a capacidade de desenvolver um pensamento complexo capaz, sobretudo, de superar o pensamento simplificado e sua lógica simplificadora. O pensamento complexo, retroalimentado pela dinâmica da incompletude e da indeterminação, questiona a fragmentação do conhecimento disciplinar. Um conhecimento que fez com que cada área de conhecimento criasse seu território próprio, com saberes e poderes absolutos, generalizações inquestionáveis e uma hiperespecialização que nega as novidades e as interdependências entre os saberes.

É com esse significado que Morin (2001, p. 190-191) afirma que "O desafio da complexidade nos faz renunciar para sempre ao mito da elucidação total do universo, mas nos encoraja a prosseguir na aventura do conhecimento que é o diálogo com o universo. O diálogo com o universo é a própria racionalidade".

O pensamento complexo implica desacomodação, deseja conhecer as variáveis com caráter de relatividade e predispõe o ser humano ao diálogo, ao embate de ideias, possibilitando a confrontação e a complementação de saberes.

Realidades indeterminadas são também parceiras da incompletude. Realidades dinâmicas, não mais abarcáveis em concepções de verdades fechadas e inquestionáveis, convidam para novos e diferentes esforços no reconhecimento da existência de articulações que, por sua vez, permitem reunir e 
interconectar diferentes conhecimentos. A percepção de articulações é também convite para tirar conhecimentos fragmentados de seu isolamento, para que possam ser visualizados como complementares, porque multirreferenciais e multidimensionais. E esse diferente modo de conceber e explicar as realidades não ignora a existência e nem a importância de certezas nos conhecimentos. Para Morin e Le Moigne (2000), juntamente com as certezas cabe reconhecer a desordem e a eventualidade, com o fim de admitir a presença da incerteza no conhecimento.

Para os autores:

Esse pensamento da complexidade não é absolutamente um pensamento que expulsa a certeza para colocar a incerteza, que expulsa a separação para colocá-la no lugar da inseparabilidade, que expulsa a lógica para autorizar todas as transgressões. A caminhada consiste, ao contrário, em fazer um ir e vir incessante entre certezas e incertezas, entre o elementar e o global, entre o separável e o inseparável. (MORIN; LE MOIGNE, 2000, p. 205).

Os autores entendem que a complexidade não é uma saída única e nem uma boa nova de salvação, nem para problemáticas de compreensão das realidades e dos fenômenos e nem para problemas educacionais. A complexidade é um desafio para pensar a dinâmica do conhecimento, já que para Morin (1986, p. 168) “o verdadeiro conhecimento é aquele que reconhece, em seu seio, a presença da incerteza e da ignorância", e mais, reconhece que "a consciência dos limites do conhecimento abre-nos o universo do conhecimento ao invés de fechá-lo".

Conhecimentos abertos e dinâmicos, incertezas, possibilidades de diálogo, o reconhecimento de fronteiras e interdependências questionam a noção de objetividade e a existência de conhecimentos objetivos sobre as realidades. Se a concepção de conhecimento objetivo está posta em questão, então a pretensão da ciência moderna de entender a cognição como representação, fazendo da mente um espelho capaz de refletir com fidedignidade o mundo ao nosso redor, já não pode mais servir de base e modelo epistemológico, pedagógico e educativo.

Na concepção representacionista, segundo Varela, Thompson e Rosch (2003), ${ }^{3}$ o conhecimento é um dado preexistente, um saber que já está pronto e que pode ser transmitido.

Ainda segundo Varela, Thompson e Rosch (2003), não é possível compreender a cognição por meio de um modelo de representação do pensamento segundo o qual os pensamentos são representações de um mundo estático e definido objetivamente. Para os autores, a realidade não tem uma delimitação exterior à mente que a representa, como se todo objeto representado tivesse sua própria estrutura e fosse independente da ideia que o representa. Para eles, o conhecimento resulta da interação entre sujeitos e realidades, já que “cognição não é representação, mas ação incorporada, e que o mundo que conhecemos não é predeterminado, mas atuado por meio de nossa história de acoplamento estrutural" (VARELA; THOMPSON; ROSCH, 2003, p. 205). 
Uma interação pela qual os sujeitos atuam sobre as realidades reorganizando o conhecimento em função das transformações que produzem nessas realidades. O conhecimento das "coisas" não como capacidade de representar realidades prontas, mas como fruto de nossas ações e interpretações, uma atividade histórica que emerge da história de ações humanas, de práticas humanas recorrentes. Conhecimento, segundo os autores, significa a história das experiências humanas que efetivamente significam o sentido das realidades, o sentido do mundo e o sentido humano.

Se o mundo é uma construção humana e já não é um mundo estável, pronto a ser representado e desvendado, estamos diante da necessidade de um diferente fazer pedagógico e educativo. Um fazer que não possa restringir-se à transmissão passiva, mas que considere a dinâmica do mundo a partir da interação do sujeito com esse mundo. Aprendizagem como experiência formativa, longe de ser prisioneira de um sistema formal de transmissões, implica o reconhecimento da existência de uma dinâmica própria ao mundo humano. Mas, retornando à nossa problemática, como, com base na complexidade, desenvolver ações pedagógicas capazes de refletir sobre os conhecimentos? Que diferentes concepções, que mudanças de mentalidade poderiam mobilizar os educadores, a fim de envolverem a si e aos estudantes nessa emergente dinâmica dos conhecimentos? As alternativas, em frente a esses desafios, precisam considerar a advertência de Morin e Le Moigne (2000, p. 90), que assevera que "a incapacidade de reconhecer, tratar e pensar a complexidade é um resultado do nosso sistema educativo. Ele ensina a validar toda percepção, toda descrição, toda explicação pela clareza e distinção".

Entendemos o pensamento complexo como possibilidade formativa, porque pode nos colocar na trilha da responsabilidade, não como algo eventual, mas presente e indicativo da liberdade para escolher ficar ou ir além.

\section{Complexidade e possibilidades formativas}

Diante das problemáticas levantadas e do leque de possibilidade formativas vislumbradas a partir da complexidade, as reflexões a seguir sinalizam como destaques: a importância de diferentes mentalidades e concepções acerca do ser humano, particularmente no reconhecimento de que cada aluno possui em si uma singularidade, e mais, que é capaz de produzir singularidades, e por isso o espaço da sala de aula deve ser muito mais um espaço de encontro entre indivíduos do que entre disciplinas. Também daremos destaque, a partir desse reconhecimento de cada aluno como sistema vivo complexo e auto-organizativo, à existência concreta e efetiva de condições para entender as relações entre o conhecido e o desconhecido. Um entendimento potencializado por ações pedagógicas e 
educativas de constante interrogação sobre as possibilidades de conhecer o conhecimento e de ressignificar o aprender, para muito além de conhecer suas funções e finalidades utilitaristas.

Não é certamente uma inverdade afirmar que, de maneira geral, as atividades realizadas pelas escolas visando à homogeneização estão compromissadas com a ordem, com conhecimentos a serem transmitidos e com a importância da hierarquização. Ao priorizarem essas concepções, como se fossem inerentes aos conteúdos escolares, semeiam a ideia de que as coisas e a realidade são igual e naturalmente ordenadas, estáveis, hierarquizadas e fragmentadas, e, por isso mesmo, podem ser elucidadas e clarificadas por completo. Ao priorizarem a existência de parâmetros ordenadores, desconsideram as inter-relações, as interdependências, as emergências, a complexidade, o desiquilíbrio e a dinâmica. A privatização do destino humano descrita por Bauman (2005, p. 9) assume nas interrelações da escola um significado ainda mais nefasto: "Em nossa época líquido-moderna, o mundo em nossa volta está repartido em fragmentos mal coordenados, enquanto as nossas existências individuais são fatiadas numa sucessão de episódios fragilmente conectados.”

Epistemologicamente, a tendência é conceber os conhecimentos como se existem "lá fora", recebidos de fora, confirmando a lógica de que o aprender é resultado de recebimentos via ensino. Ensinar e educar tornaram-se sinônimos e significam transmissão de saberes pré-existentes. Essa transmissão implica práticas pedagógicas expressas em linguagens que definem tudo com absoluta clareza. Significam posições fechadas, ignorando a experiência personalizada do estar conhecendo e da percepção da existência de inter-relações como potencializadores da compreensão de fenômenos.

Não estamos negando a importância das certezas, das definições e mesmo das tarefas instrucionais. Não há como eliminar, de forma radical, o formalismo, as regras e a instrução, mas, como escreve Morin (2001, p. 179), é fundamental reconhecer a existência de relações complementares "entre as noções de ordem, de desordem e de organização".

Isso significa admitir que todo e qualquer fenômeno, seja biológico ou social, apresenta imensuráveis interações, tornando frágeis e simplistas todas as proposições de homogeneização e/ou de caráter universalista. Reconhecer a existência de perturbações, de ruídos e da dinâmica é uma das metas da complexidade. Isso permite entender que cada aluno possui em si uma singularidade, e mais, que é capaz de produzir singularidades, pois sua vida é cheia de incidentes e de desvios que o obrigam a improvisar, a apostar, a correr riscos, a temer e a construir estratégias alternativas.

Se a vida é complexa, a vida de cada aluno também o é, e sua compreensão não é possível pela via da mera sistematização de conhecimentos prontos. Significa que a vida e o viver não estão definidos, que oscilam entre o conhecido e o desconhecido. O aluno, como ser humano, que se organiza 
como sistema vivo complexo, precisa entender a relação entre o conhecido e o desconhecido. Precisa compreender que sua relação com o conhecido é também uma relação com o desconhecido. Ao admitir-se a impossibilidade de conhecimentos completos, ocorrem aberturas para se reconhecer a emergência de diferentes vozes presentes nas e como experiências formativas.

A complexidade é uma oportunidade para se abandonar, como ação educativa e pedagógica, o mero enquadramento às lógicas rígidas, às verdades absolutas, para então se qualificar o potencial humano da compreensão, e não, prioritariamente, habilidades de repetição. Para Morin (2004, p. 22), “A educação deve favorecer a aptidão natural da mente" e viabilizar "o livre exercício da faculdade mais comum e mais ativa na infância e na adolescência, a curiosidade, que, muito frequentemente, é aniquilada pela instrução".

Uma educação escolar que se alimenta da complexidade toma como base de suas ações pedagógicas e educativas a importância do desenvolvimento de formas relacionais para com os conhecimentos, como enfoque mais relevante do que conhecer coisas, fenômenos ou mesmo conhecer leis científicas. Por isso, a complexidade exige uma "reformulação do pensamento", e esta, conforme assegura Morin (2013, p. 184), "comporta um caráter epistemológico e reflexivo". Nesse contexto escolar, o desafio pedagógico não fica condicionado à elaboração de currículos como se fossem programas, mas fundamentalmente se dirige à dinâmica de paradigmas epistemológicos que orientam e sustentam estes currículos. Um desafio que interroga a possibilidade do conhecer o conhecimento para muito além de conhecer suas funções e finalidades utilitaristas. Essas interrogações jogam professor e aluno na aventura do conhecimento, ou seja, aproximam e integram o "conhecedor em seu conhecimento"; por isso Morin (2005, p. 31) enuncia que o problema do conhecimento, para a educação, é "um princípio e uma necessidade permanente". Essa diferente relação para com o conhecimento, conhecer o conhecer, que emerge do paradigma da complexidade, sinaliza uma nova racionalidade no âmbito do saber-fazer escolar, com implicações também na ressignificação do humano.

Nessa ressignificação, aprender já não é a mesma coisa que adquirir conhecimento através do recebimento de informações, tampouco por meio da inculcação de métodos ou da prescrição de regras ou receitas. Aprender também não é a mesma coisa que resolver problemas, o que envolve a tomada de decisões sobre como superar a distância entre um determinado ponto, no qual se está, e o estado a que se deseja chegar. A aprendência é caracterizada por Varela, Thompson e Rosch (2003, p. 210), diante da crise relacional, como uma oportunidade efetiva de compartilhar, pois "o papel central da 
inteligência humana deixou de ser a capacidade para resolver problemas para ser a capacidade de entrar num mundo compartilhado". Nessa concepção de Varela, Thompson e Rosch, evidencia-se o quanto o mundo vivencial de cada ser humano emerge e está imbricado com e junto ao mundo vivencial de outros. Mas essa percepção não é evidente e natural; fazê-la requer formação, e as experiências formativas compartilhadas possibilitam o compartilhamento da compreensão humana na condição de bem comum. A aprendizagem acontece, conforme Maturana e Varela (1995, p. 72) quando e enquanto ocorre "uma ação efetiva, uma ação que permita a um ser vivo continuar sua existência em determinado meio ao produzir aí se mundo" (grifo dos autores). É essa operacionalidade do ser vivo em seu domínio de existência que lhe permite não só continuar vivo, mas, na vivência, melhorar seu mundo.

Melhorar o mundo é construir mundos fazendo mundos de convivência e isso envolve dinâmicas interpretativas, condição de observador e criador de conhecimentos. Então, conhecer é reconstruir; conhecimento tem a ver com reconstrução, como escreveu Morin (2002, p. 125):

Todo conhecimento, inclusive toda percepção, é tradução e reconstrução, isto é, interpretação. Uma realidade de conjunto só se manifesta através de teorias, interpretações, sistemas de pensamento. Todo o conhecimento de uma realidade política, econômica, social, cultural depende de sistemas de interpretação da política, da economia, da sociedade, da cultura, sistemas que são interdependentes de um sistema de interpretação da história.

Sendo o conhecimento resultado de interpretações de sistemas interdependentes, não lhe cabe o sentimento de posse ou de propriedade. Nenhum ser humano, nenhum professor, mesmo em sua formação específica, pode atribuir a si mesmo o status de proprietário de uma determinada disciplina. Sentir-se proprietário significa negar a participação, a construção interpretativa e histórica, para, de forma arrogante, atribuir-se o direto de emissor e transmissor de verdades sob a forma de conhecimentos prontos e acabados.

Professores, prisioneiros de e em disciplinas, além de se manterem fechados entre as fronteiras artificiais de seus conhecimentos, também apresentam dificuldades em seus relacionamentos interpessoais. Enclausurados e dominados pela estrutura rígida, são reféns de dispositivos normativos e de controle e raramente se dão conta das problemáticas epistemológicas envolvidas nas concepções de conhecimentos e nas concepções de ser humano, de vida e de mundo.

Grande parte da fragilidade compreensiva dessas concepções se localiza nos processos formativos dos professores e educadores. A formação disciplinar dos educadores, normalmente assentada sobre modelos que privilegiam a especificidade da área ao invés de sua interdependência, é, certamente, uma das principais barreiras para a operacionalização de práticas pedagógicas possíveis no seio da complexidade. A 
complexidade subsidia uma melhor compreensão dos fenômenos, qualificando o olhar sobre eles, porque aberta à busca de aportes em diferentes áreas do conhecimento.

Os obstáculos formativos são complexos, e toda e qualquer solução simplista e em caráter de urgência não passa de um paliativo intempestivo. Processos formativos alternativos implicam mudança de mentalidade, que envolve mudanças de concepções de uma relação pedagógica baseada na transmissão de conhecimentos por parte de determinada disciplina para uma relação participativa e construtiva. Essa mudança nas ações pedagógicas terá êxito crescente à medida que ocorrerem também mudanças nas concepções de aprendizagem, de tal sorte que passem a entendidas como inerentes às experiências de vida. Ou seja, ao admitir que a capacidade de aprendizagem de qualquer sistema vivo envolve seu operar biológico, seu operar ambiental e relacional e sua dinâmica racional epistêmica. Essa aprendizagem, de características processuais, concebe-se profundamente enraizada, na sua identidade básica, entre processos vitais e processos cognitivos (MATURANA; VARELA, 1995). Requer a mudança das concepções de ser humano que reduzem sua capacidade cognitiva ao papel de receptor e memorizador para a de um ser humano capaz de auto-organização. Requer também a compreensão de que nem o mundo nem os conhecimentos são pré-existentes, mas sim construções humanas. Por isso, resumir o aprender à superficialidade significa consignar o analfabetismo, tanto em temáticas científicas quanto nas pertencentes ao universo das experiências de vida. Esse tipo de aprender, tradicional e mecanicista, de saberes codificados a serem apreendidos, coisificando e objetivando o real, restringe-se à memorização de fórmulas e de teoremas sem qualquer expectativa em relação à sua aplicabilidade na vida.

Um fazer pedagógico diferente e educativo, que vá além do intercâmbio entre disciplinas, passa a ser um recurso na construção de conhecimentos que emergem da compreensão profunda da complexidade das coisas, da vida e das realidades. É nesse sentido que se considera relevante e digno reconhecer que todas as posições individuais merecem respeito e reconhecimento. Superar o estado de rigidez dos educadores, enquadrados em categorias mecanicistas, é talvez um dos obstáculos mais difíceis a serem superados, para que o grau de liberdade dos alunos seja aumentado no que concerne à manifestação de suas experiências de vida, aos modos singulares de conhecer e também quanto ao que conhecer.

É o respeito a um princípio básico legado pela ciência cognitiva, segundo o qual cada indivíduo aprende conforme sua capacidade de relacionar, de integrar, de associar, de conectar informações e de transformá-las em novos conhecimentos.

$\mathrm{Na}$ construção de alternativas formativas, o reconhecimento dos limites e da interdependência entre as disciplinas abre as portas para a integração dos conhecimentos, porque admite o 
questionamento de suas bases. Questionar os pressupostos do conhecimento é sintonizá-lo com o pensamento complexo, que nos diz que o conhecimento nunca estará completo e que a racionalidade cartesiana tem limites. Significa olhar as disciplinas de forma diferente, procurando visualizar as interconexões por entre as evidências das distinções.

O suporte dessa premissa é a dinâmica fundamental que viabiliza a predominância do respeito ao modo de ser de cada professor e de cada aluno, um jeito de caminhar a ser empreendido por cada um em busca de autonomia. São diferentes experiências formativas que instigam ambos, professores e alunos, a compreender que o espaço da sala de aula é muito mais um espaço de encontro entre indivíduos do que entre disciplinas. Experiências formativas que transformam o espaço da sala de aula em um local de convívio assentado no conversar espontâneo e na colaboração de fazeres e aprendizagens.

Afastados dos padrões mecânicos que insistem na homogeneização, a complexidade permite que tanto alunos quanto professores estejam atentos às sutilezas e singularidades das coisas e dos fenômenos, bem como da nossa inseparabilidade em relação às suas ocorrências. Esta atenção nos coloca na trilha da responsabilidade. É a noção de responsabilidade pela construção das realidades, nascida na teoria do caos (LORENZ, 1996), ao afirmar que os sistemas caóticos e complexos são fortemente influenciados por nós. Formas de influência ainda desconhecidas, mas que emergem da presença das interações, tal qual são desconhecidas as influências formativas - e sua magnitude - de professores e educadores sobre outros seres humanos.

Do princípio dessa responsabilidade afloram efetivamente possibilidades ampliadas para o respeito e o desapego. Uma reconfiguração dos sentires, agora espontâneos, no respeito ao dizer do outro, que não terá mais tão somente uma presença ocasional, mas será marcado pela regularidade coerente e repetitiva. Desapegar-se de seus próprios dizeres gera uma forma pedagógica e relacional que inibe a homogeneidade e permite enxergar em cada aluno a sua condição de ser humano singular, sem que isso signifique a valorização da diferença como desigualdade, o que reabriria as portas para novas formas de discriminação.

Essa diferente mentalidade pedagógica e educativa sintoniza com um dos sonhos de Morin (2001, p. 33):

A esse novo espírito científico, será preciso acrescentar a renovação do espírito da cultura das humanidades. Não esqueçamos que a cultura das humanidades favorece a aptidão para a abertura a todos os grandes problemas, para meditar sobre o saber e para integrá-lo à própria vida, de modo a melhor explicar, correlativamente, a própria conduta e o conhecimento de si. 
Reafirma-se que educar, como escreveu Severino (2006, p. 621), é “instruir-se, colocar-se ao lado de, desenvolver-se, dar-se um ser" ciente da impossibilidade de prever e controlar, mas com as fronteiras abertas para a criatividade. A criatividade se alimenta da dúvida, do inconformismo, do desejo de profanar. A criatividade fertilizada pela dúvida aceita os enganos, a incompletude, a incerteza e o erro como algo que se possa e se queira corrigir. Já não fazem sentido os preconceitos, os comportamentos indesejados em nome da negação de dispositivos de poder e controle e nem a vergonha pelo fracasso, o que, por sua vez, permite a revisão de repetências.

A interdependência, como esteio dos fenômenos e das realidades, preconizada na teoria do caos, coloca-nos no tropeço das fronteiras, como espaço ambíguo de permanência e passagem, não mais como barreira divisória, mas como algo permeável e fluido, com presença da liberdade para escolher ficar ou ir além. Esse é um dos sonhos de Maturana (2000, p. 104) ao escrever:

Para transpormos fronteiras, precisamos de liberdade. Isso significa que temos de nos comportar de maneira que possamos emergir, sem que tenhamos medo de desaparecer no que fazemos. Assim, podemos voltar ou ficar lá; ou podemos ir além de juntar coisas que de outra maneira não seriam juntadas, porque campos diferentes não se relacionam, mas somos nós, seres humanos, que os relacionamos. (grifos nossos).

Fragmentar ou juntar o tecido junto, envolve nossa capacidade, nosso potencial de compreensão, nossa condição humana. Como é noutro tempo, como um tempo primordial, o juntar o tecido junto, que fora fragmentado, constitui um novo tecer, novas tecituras constitutivas. E isso as experiências formativas podem. É uma aventura humana que se realiza na investigação profunda da complexidade existencial, possível quando transpomos as fronteiras embalados nos braços da liberdade.

\section{Considerações finais}

Nossa problemática quis salientar a importância de diferentes abordagens do conhecimento, não mais especificamente em sua vertente utilitarista, mas entendendo como cada vez mais imprescindível conhecer e compreender os conhecimentos. Desejar conhecer os conhecimentos, tendo vista que se relacionar com os conhecimentos é uma espécie de via conceitual que possibilita conhecer a cognoscibilidade e os sentidos das coisas e da vida, considerando que podem apresentar-se como formas janelares de conhecimentos a serem admitidos como "verdadeiros" e ou científicos.

$\mathrm{Na}$ atualidade, o conhecimento dos fenômenos, sejam naturais e/ou os presentes nas organizações humanas, todos reconhecidamente complexos, exige concepções de natureza epistemológica e metodológica diversas e variadas. 
No complexo contexto das dinâmicas desses fenômenos, os especialistas disciplinares percebem sua estreiteza conceitual quando confrontados com a diversidade e a multireferencialidade neles envolvidas. Torna-se cada vez mais indispensável encontrar princípios e vínculos de unidade entre as diferentes ciências e disciplinas, como também a compreensão de que a sensibilidade colaborativa é um aliado imprescindível para o conhecimento dos conhecimentos. Mas reconhecer a interdependência e a cooperação requer formação. Uma formação não mais atrelada a organizações curriculares fechadas que, além de impedirem avanços da formação pedagógica, tendem a oferecer formações defasadas.

As instituições de ensino superior, que ainda vivem na era da especialização, que agregam professores limitados em sua formação geral e científica, só podem mesmo aprofundar o processo da fragmentação dos conhecimentos, reforçar a lógica dos dispositivos de controle e esmerar-se em mostrar a utilidade do conhecimento.

Superar os rancores hierárquicos, a fragmentação e o individualismo disciplinar, a completude de conhecimentos e a competição como fator central na natureza e nas organizações humanas passa por experiências formativas baseadas em outros imaginários, capazes de desenvolver outros sentires e, então, outros fazeres. Experiências formativas de interdependência que reconhecem a existência de diferentes realidades, regidas por lógicas e leis diferentes, validadas em contextos espaciais e temporais determinados, podem conduzir a atitudes abertas, a atitudes de respeito e de colaboração em que a realidade emerge como constituinte colaborativo.

É momento de as escolas e os professores aceitarem a aventura do pensamento complexo, como uma aventura colaborativa cujo objetivo seja relacionar variáveis diferentes, para ligar os conhecimentos. É preciso correr o risco dessa aventura, porque é uma aventura humana e humanizadora. Nessa aventura e no desejo de compreender melhor a complexa condição humana, já

não existe, de agora em diante, mais nenhuma pergunta que não seria respondida de forma diferente por diferentes paradigmas. [...] A validade das constatações feitas no interior de uma versão de mundo é relativa às premissas dessa versão: no contexto das premissas escolhidas, as afirmações fazem sentido; no contexto de outras premissas, não. (WELSCH, 2007, p. 247-249).

No contexto da complexidade, a formação de professores navega nos oceanos do reconhecimento mútuo em substituição às lógicas do exercício da autoridade com base no medo da carência e da dor.

O desafio de conhecer o conhecimento acontece em ambientes de confiança e nas coerências dos fazeres em sala de aula, ancorados no respeito ao dizer do outro. Nesse desafio, já não faz sentido o desejo do poder e da manipulação com base em argumentos racionais e premissas únicas.

Ações pedagógicas com base na complexidade são desenvolvidas tendo a compreensão como eixo central da convivência em colaboração. 
Ações pedagógicas com base na aceitação das diferentes disciplinas, na aceitação das singularidades e da diversidade são construtoras de sensibilidade e de corresponsabilidade, em outras palavras, de vivências éticas.

São as experiências formativas, carregadas de seriedade e responsabilidade, que, no universo da complexidade, tornam possível um fazer pedagógico de colaboração embasado no mútuo respeito. Então a esperança de Maturana e Dávila Yáñez (2009, p. 50) fará não só sentido, será efetivada na convivência: “O futuro da humanidade não são os meninos, as meninas e os jovens, mas nós os adultos com os quais eles convivem, pois eles, por sua vez, serão como adultos, parecendo-se ou diferenciando-se de nós, conforme sejamos nós mesmos adultos em nosso conviver com eles."

\section{Notas}

${ }^{1}$ Proposições de Descartes ante a complexidade da realidade, ou regras do método cartesiano, que foram tomadas como referência pela ciência moderna: 1) "[...] nunca aceitar algo como verdadeiro que eu não conhecesse claramente como tal; ou seja, de evitar cuidadosamente a pressa e a prevenção, e de nada fazer constar de meus juízos que não se apresentasse tão clara e distintamente a meu espírito que eu não tivesse motivo algum de duvidar dele; 2) [...] repartir cada uma das dificuldades que eu analisasse em tantas parcelas quantas fossem possíveis e necessárias a fim de melhor solucioná-las; 3) [...] conduzir por ordem meus pensamentos, iniciando pelos objetos mais simples e mais fáceis de conhecer, para elevar-me, pouco a pouco, como galgando degraus, até o conhecimento dos mais compostos, e presumindo até mesmo uma ordem entre os que não se precedem naturalmente uns aos outros; 4) [...] efetuar em toda a parte relações metódicas tão completas e revisões tão gerais nas quais eu tivesse a certeza de nada omitir. Essas longas séries de razões, todas simples e fáceis, que os geômetras costumam utilizar para chegar às suas mais difíceis demonstrações [...]”. (DESCARTES, 2004, p. 49-50).

${ }^{2}$ Mas é radicalmente a dúvida metódica que leva à convicção do eu pensante, que faz volver-se o eu para dentro de si, para o trato exclusivo de si mesmo, que confere o aporte estrutural para o dentro e o fora. Tal divisão possibilita o conceito de mundo exterior. "O dualismo é tão rigoroso que, nesta visão, o homem se assemelha a uma máquina animada por um eu pensante. [...] Se corpo e alma são apenas dois entes justapostos, podem ser estudados um independente do outro", o que causa a divisão das ciências e do ensino em dois blocos separados: "[...] as faculdades que se ocupam do estudo das ciências do espírito e as faculdades que se ocupam do estudo do mundo material, inclusive do corpo humano" (ZILLES, 2003, p. 141-142).

${ }_{3}^{3}$ Aqui no referimos especialmente à parte do livro que trata "A mente corpórea". Nela os autores apresentam uma nova abordagem para a ciência da cognição, propondo a enacção. Com base na enacção, a cognição é uma ação corporalizada, ou seja, o conhecimento é fruto da interação entre o sujeito que conhece e a realidade sobre a qual atua e das transformações que produz nessa realidade. 


\section{Referências}

BAUMAN, Zigmunt. Identidade: entrevista a Benedetto Vecchi. Rio de Janeiro: Zahar, 2005.

DESCARTES, René. Discurso do método. São Paulo: Nova Cultural, 2004. Coleção Os Pensadores.

JAPIASSU, Hilton. O sonho transdisciplinar e as razões da filosofia. Rio de Janeiro: Imago, 2006.

LÉVY, Pierre. A inteligência coletiva: por uma antropologia do ciberespaço. São Paulo: Loyola, 1998.

LORENZ, Edward. A essência do caos. Brasília: Unb, 1996.

MATURANA, Humberto; VARELA, Francisco. A árvore do conhecimento: as bases biológicas do conhecimento humano. São Paulo, Campinas: Psi II, 1995.

MATURANA, Humberto. Cognição e transdisplinaridade. In: MELLO, M.F.; BARROS, V. M.; SOMMERMANNN, A. (Org.) Educação e transdisciplinaridade. Brasília: Unesco, 2000. p. 79-110.

MATURANA, Humberto; DÁVILA YÁÑEZ, Ximena. Habitar Humano: em seis ensaios de Biologia Cultural. São Paulo: Palas Athena, 2009.

MORIN, Edgar; LE MOIGNE, Jean-Louis. A inteligência da complexidade. São Paulo: Peirópolis, 2000 .

MORIN, Edgar; KERN, Anne Brigitte. Terra Pátria. Porto Alegre: Sulina, 2002

MORIN, Edgar. Para sair do séc. XX. Tradução: Vera Azambuja Harvey. Rio de Janeiro: Nova Fronteira, 1986.

. Ciência com consciência. 5. ed., Rio de Janeiro: Bertrand Brasil 2001.

. O problema epistemológico da complexidade. Publicações Europa-América, 2002.

. A cabeça bem-feita: repensar a reforma, reformar o pensamento. Rio de Janeiro: Bertrand Brasil, 2004.

. Os sete saberes necessários à educação do futuro. 10. ed., São Paulo: Cortez; Brasília, DF: Unesco, 2005.

. A via para o futuro da humanidade. Rio de Janeiro: Bertrand Brasil, 2013.

PRIGOGINE, Ilya. O fim das certezas: tempo, caos e as leis da natureza. São Paulo: Universidade Estadual Paulista, 1996. 


\section{Roque Strieder, Clenio Lago e Paulino Eidt}

ROSSI, Paolo. Naufrágios sem espectador. A ideia de progresso. Tradução: Álvaro Lorencini. São Paulo: Unesp, 2000.

SNOW, Charles Percy. As duas culturas e uma segunda leitura. Tradução: Geraldo G. de Souza e Renato de A. Rezende. São Paulo: Edusp, 1995.

SEVERINO, Antônio Joaquim. A busca do sentido da formação humana: tarefa da Filosofia da Educação. Educação e Pesquisa, São Paulo, v. 32, n. 3, p. 619-634, set./dez. 2006.

VARELA, Francisco; THOMPSON, Evan; ROSCH, Eleanor. A Mente Incorporada: Ciências Cognitivas e Experiência Humana. Porto Alegre: Artmed, 2003.

WELSCH, Wolgang. Mudança estrutural nas Ciências Humanas: diagnóstico e sugestões. In: Educação, Porto Alegre/RS, ano XXX, v. 30, n. 2 (62), p. 237-258, maio/ago. 2007.

ZILLES, Urbano. Teoria do conhecimento. 3. ed. Porto Alegre: Edipucrs, 1998. 


\section{Complexity and formative experiences}

\section{Abstract}

The contemporaneity is characterized by instability and diversity calling into question certainties and truths proposed in modernity. We recognize that the reality of things and phenomena become effective as a set of events, interactions, retroactions and chances. This different frame extends the need for revision of the epistemological foundations that sustain educational practices and give them sense. The complex thinking is an alternative option for acting as a counterpoint to classical science and its reductionist logic and knowledge compartmentalization, as well as to answer to contemporary epistemological and educational challenges. It aims to associate different areas and forms of knowledge, without, however merge them, distinguishing without separating the several disciplines and instances of the realities. This study, in theoretical references, highlights the relevance of complex approaches to support formative experiences because also able to produce complexities in reflections about educational issues. We conclude that formative possibilities from complexity potentialize the resignification of human's conception and the understanding of its singularity in interdependence; The understanding that pedagogical and educational activities is a constant interrogation about the possibilities of knowing the knowledge and reframe learning, far beyond knowing its functions and utilitarian purposes; and, as a formative possibility, places us on the trail of responsibility, not as something eventual, but present and indicative of freedom to choose to stay or go beyond.

Keywords: Education. Complexity. Formative Experiences.

\section{Roque Strieder}

E-mail: roque.strieder@unoesc.edu.br

Clenio Lago

E-mail: clenio.lago@unoesc.edu.br

Paulino Eidt

E-mail: paulinoeidt1@gmail.com

\section{Complejo y experiencias de formación}

\section{Resumen}

La contemporaneidad caracterizase por la inestabilidad y por la diversidad poniendo en cuestión certezas y verdades propuestas en la modernidad. Reconocemos que la realidad de las cosas y los fenómenos es eficaz como como un tejido de eventos, acciones, interacciones, y las ocasiones retroacciones. Este marco diferente que se extiende la necesidad revisión de los fundamentos epistemológicos que prestan apoyo a las prácticas educativas y darles un significado. El pensamiento complejo es una opción alternativa para actuar como contrapunto a la ciencia clásica y su lógica reduccionista y la compartimentación de los conocimientos, así como para responder a los desafíos epistemológicos y educativos contemporánea. Su objetivo es asociar varias áreas y diversas disciplinas y las instancias de las realidades. El estudio, en los marcos teóricos resalta la relevancia de los enfoques complejos como experiencias de formación de apoyo porque también capaz de producir complejidades en las reflexiones sobre temas educativos. Llegamos a la conclusión de que las posibilidades de formación de la complejidad potenciar la reinterpretación del concepto de ser humano y la comprensión de su singularidad interdependencia; el entendimiento de que las actividades de enseñanza y educativos es una pregunta constante sobre las posibilidades de conocer el conocimiento y replantear el aprendizaje, mucho más allá de conocer sus funciones y fines utilitarios; y, como posibilidad formativa, nos pone en el camino de la responsabilidad, no como algo posible, pero presente e indicativa de la libertad en optar por quedarse o ir más allá.

Palabras clave: Educación. Complejidad. Experiencias formativas.

Enviado em: 29/06/2016

Versão Final Enviada em: 10/10/2016

Aprovado em: 06/04/2017 